\title{
The role of local government in the community engagement of a renewable energy company in South Africa
}

\author{
Bryan Michael Kenneth Robinson ${ }^{1 *}$ (iD) and Siân Stephens ${ }^{2}$ \\ 1. Business School, Nelson Mandela University, Port Elizabeth, South Africa \\ 2. Business School, Middlesex University, London, United Kingdom
}

\begin{abstract}
Adopting a qualitative case study approach of a renewable energy company in South Africa, the research investigated community engagement within the tripartite relationship of a wind farm, the communities around $i t$, and the local government. It was found that local government played a moderating role in the community engagement efforts of the wind farm, which had to comply with certain engagement protocols determined by local government. Local government also played a mediating role in corporate community engagement, as the wind farm developed its engagement strategy in alignment with local government's policies and acted as a 'dot-connector' between local government and communities. The wind farm played a reciprocal mediating role on local government's own engagement with their communities in the face of local government's inefficiencies, and complemented service delivery outcomes. The wind farm's engagement strategy thus enabled local development, which was appreciated by communities and local government.
\end{abstract}

Keywords: Renewable energy, corporate community engagement, local government, sustainable development, South Africa

Journal of Energy in Southern Africa 32(3): 14-23

DOI: https://dx.doi.org/10.17159/2413-3051/2021/v32i3a9403

Published by the University of Cape Town ISSN:2413-3051 https://journals.assaf.org.za/jesa

This work is licensed under a Creative Commons Attribution-ShareAlike 4.0 International Licence

Sponsored by the Department of Science and Innovation

Corresponding author: Tel.: +27 (0) 78655 7465; email: bryan.robinson@mandela.ac.za 


\section{Introduction}

South Africa's Renewable Energy Independent Power Producer Procurement Programme (REIPPP) has not only the potential to reduce carbon emissions in energy production but holds the promise of contributing to local economic development efforts (Wlokas et al. 2017). In order to better understand this impact, this qualitative case study and thematic analysis scrutinised the community engagement endeavours of a wind farm initiated under the REIPPP. It did so from the perspective of the tripartite relationship between the wind farm, the local government and the various communities in the vicinity of the wind farm's operations.

The relationship between business and its mosaic of stakeholders continues to occupy researchers' attention as they grapple to better understand the underlying factors that arbitrate these relationships. Dedicated engagement by companies with community stakeholders holds the promise to contribute to the well-being of communities, especially in countries with urgent development priorities (Stirling et al. 2016). An effective corporate community engagement strategy has the propensity to build close relationships between companies and their communities (Liu et al. 2013) and to generate civic wealth (Lumpkin and Bacq 2019), yet the benefits are not clearly understood which suggests further inquiry in this regard is necessary. The role of local government, as one of businesses' multiple stakeholders in the dynamics of this corporate community engagement, is an important subject worthy of further research.

The following section presents the wind farm and discusses the socio-economic and policy context of its operations. The concepts of corporate community engagement, the role of local government in relation to business and society in this tripartite relationship are then considered, and this tripartite relationship in the South African setting discussed. This is followed by a discussion of methodology and findings, from which conclusions are drawn relating to the nature and impact of corporate engagement by the wind farm within the tripartite relationship.

\section{The wind farm, its communities and local government}

In order to contextualise the literature discourse, some background to the case study on the South African wind farm and its tripartite relationship with surrounding communities within the $50 \mathrm{~km}$ ringfenced radius of the windfarm and the local government is useful. Communities refer to residents from a relatively poorer rural area and rural coastal town, an affluent coastal resort town, a rural agricultural community where the wind turbines were erected, and a neighbouring town. The wind farm is situated in a scenic, rural, coastal area, in an environment of extreme disparities in community wealth - not uncommon in South Africa. The medium-sized wind farm, with 32 turbines, was constructed between 2013 and 2015 and was connected to the national electricity grid in 2015 . It is a consequence of South Africa's move to renewable energy and was one of 28 wind farms approved by the South African National Department of Mineral Resources and Energy during its first REIPPP (Company X website 2020). A material consideration in the REIPPP, and as a consequence a factor in the awarding of bids, was the contribution the programme would make to national development objectives, which included job creation, social upliftment, and economic transformation through broader economic ownership (IPP Projects 2020; Department of Mineral Resources and Energy 2020; Eberhard, and Naude 2016).

The ownership of the wind farm reflects the application of some of these socio-economic objectives. It is owned by a combination of private and institutional investors, with $26.1 \%$ belonging to the wind farm's Community Development Trust, financed by the South African government's development finance institution, the Industrial Development Corporation. This community ownership, as well as a commitment by the wind farm to an additional percentage of revenue being invested in the communities, was a contributing factor to the consortium of owners being awarded the bid.

The local government for the municipal area in which the wind farm is situated has been found lacking in terms of service delivery and been found guilty of a variety of corruption-related activities in the past (Municipality X 2012). It has been described as dysfunctional by the provincial government (Municipality X 2016), although, there have been some recent marginal governance improvements (Municipality X 2018). ${ }^{1}$ These inefficiencies are particularly important to consider, as local government policy implementation, service delivery constraints, and socio-economic objectives have repercussions on the wind farm's corporate community engagement within the tripartite relationship.

\section{Corporate community engagement}

The wind farm, partly owned by the community, and with community investment obligations in terms of the REIPPP bid, had certain preliminary engagement commitments: it was required to assist in the establishment and initial management of the Community Development Trust, and to allocate a certain percentage of revenue to community investment. This was the extent of national government's influence on the wind farm's community engage- 
ment efforts, with little other guidance or parameters stipulated by national government on how it was to go about this investment in the community. As the wind farm Chief Financial Officer (personal communication to the researchers) commented: 'We're a very vanilla project, we're a Round 1 project [first stage of REIPPP] .... The downside is that you really are the Guinea Pig with everything.' It found itself in a position where it was able to craft its own community engagement strategy.

At this stage it is useful to reflect on communities from a stakeholder perspective, and community engagement from a corporate community engagement strategy perspective, as this provides some theoretical context to the engagement between the wind farm, local government, and its socio-economically diverse communities.

Stakeholder theory and the stakeholder view of the firm continues to receive attention after being popularised by R. Edward Freeman in his 1984 book Strategic management: A stakeholder approach. This is because it provides a useful lens to engage with the debate on business within society, and understanding continues to evolve on this compelling relationship, and to which our research contributes. The interrelationship between business and society is complex and a positive relationship can contribute significantly to the sustainability of organisations and have positive outcomes for society. A strategic focus on society positively impacts business sustainability and the reciprocal flow of value between companies and their stakeholders increases the value creation for all (Freudenreich et al. 2019; Nijhof et al. 2019).

Research on corporate engagement strategies continues to provide new insights on the confluence of business and society (Delannon et al. 2018; Bowen et al. 2010; Stirling et al. 2016). Corporate engagement can lie anywhere on the continuum of community engagement of 'transactional', 'transitional' and 'transformative' (Bowen et al. 2010), and empirical research has found that these corporate engagement strategies can vary from being 'passive', such as simply giving donations (Lorenz et al. 2013), to being applied in a complementary approach - an 'integrational' strategy', consisting of elements of all three strategies (Delannon et al. 2018, 719). Appropriate strategies can contribute to stronger relationships between companies and their communities and affect civic wealth (Liu et al., 2013; Lumpkin and Bacq 2019, 387).

Corporate community engagement occurs within the complex multiple-stakeholder environment companies find themselves in. The following section will examine local government as one of the critical stakeholders that influences corporate community engagement.

\section{The tripartite engagement between local government, business and communities}

This research introduces local government into the exchange between the wind farm and communities in order to investigate the role local government may have on the company's engagement efforts within this tripartite relationship. The role of local government is now considered from the perspectives of its bilateral engagement with communities and businesses, before considering the interrelationship between the tripartite parties.

The justification for governments' ongoing intervention in economies has been that markets and private institutions may make suboptimal choices, especially in the development context, hence the need for governance (Schaffner 2014). Local governments act as a planning authority and provider of welfare services, but when they are required to adopt socio-economic objectives, they become development actors, which influences the way they engage with their communities (Vasstrøm and Normann 2019).

Local government engagement efforts with their communities are a function of regional and national government policy and legislation (Christensen 2018). Other reasons for such engagement include the quest for better and more democratic outcomes from these participatory practices and the need to improve legitimacy in an environment of community activism and increasing distrust of government. Communities are also becoming more demanding of their local government representatives, necessitating engagement. Engagement may also be a desire of government to broaden the base of decision-making responsibility in order to avoid blame for poor decisions or to shift responsibility onto communities (Christensen 2018; Rolfe 2016).

Not only is government expected to be an enabler of communities, but also an enabler of markets (Miraftab 2004). It makes intuitive sense that local government could and should have some level of influence on businesses in its jurisdiction, and that local government engage with the business community, a source for employment and regional socio-economic development. The value of developing this tripartite relationship is advocated 'on the grounds that the partnership of communities and the private sector, mediated by the public sector, achieves a synergy able to overcome certain shortcomings' of achieving local economic development objectives of government (Miraftab 2004), with significant potential to create employment and stimulate local economic activity (Helmsing 2003). In view of this, local government itself has a responsibility to engage with a wide cross-section of the local business community to ensure local private sector participation and involvement in local government sustainable development objectives (Wor- 
thington et al, 2003). Researchers have gone even further, to suggest a collaborative governance approach with business, which can contribute to developing policy approaches suitable for complex social problems, while improving support for regulations by business, thus enhancing policy implementation (Kim and Darnall 2015).

In turn, corporate multi-stakeholder engagement necessitates engagement with communities as well as local government. Fruitful cooperation of the community, regimes of support - including local government, and the enterprise, would result in the creation of economic, communal, and social wealth (Lumpkin and Bacq 2019, 387).

The tripartite engagement between private business, local government and the community is an important topic which requires greater attention and to which this research aspires to contribute.

\section{Corporate community engagement and the South African context}

Corporate community engagements efforts in South Africa are a function of numerous factors. For instance, there are governmental policy measures and legislation to address historic racial inequalities, such as Black Economic Empowerment. Corporate governance guidelines contained in the King Reports on Corporate Governance requires governing bodies of organisations to be responsible corporate citizens with specific mention of community development (Institute of Directors in South Africa 2020). There are also legislated participation and economic development requirements for certain industries, such as extractive mining and petroleum (South African Government 2020). Businesses often adopt community engagement interventions to mitigate the brittle nature of violent community protests targeted towards the business community (Alexander et al. 2018; Mujere 2015). In addition, there has been a general shift towards more companies embracing community engagement in South Africa.

Corporate community engagement efforts have evolved from transactional (Bowen et al. 2010) philanthropic handouts and support of good causes, which have not contributed much to alleviating the social problems in communities, to a transformational approach of 'shared responsibility and negotiated collaboration' (Hammann 2004). However, not all South African companies have progressed to a transformational stage of community engagement, and there are a number of examples of companies failing to adopt a consultative process with communities and not collaborating when embarking on community development projects (Moloi et al. 2014). This has constrained the impact of engagement efforts on socio-economic development, due to a lack of a focussed and aligned corporate strategy for community investment (Manchidi 2015).

South Africa's national policy objectives influence local government's own socio-economic objectives. Corporate community engagement is therefore not only influenced by the government's national policy objectives and the fabric of the communities with which they interact, but also by the policies and actions of local government. This case study's intention is to interrogate this influence of local government on corporate community engagement by the wind farm.

What follows is a description of the methodology, data collection and data analysis utilised to shed light on these areas of investigation.

\section{Methodology and analysis}

A qualitative research methodology was adopted that utilised a case study design. Such a design is suitable for attaining an in-depth understanding of the engagement efforts, and the resultant outcomes, in the tripartite relationship between the wind farm, the community, and local government (Leedy and Ormrod 2005). Purposive sampling was conducted, and semi-structured interviews administered to obtain the diverse perspectives of the wind farm, the communities, and the local government on the engagement efforts of the wind farm. From the leadership of the wind farm, the Chief Executive Officer (CEO), the Chief Financial Officer (CFO) and the Community Engagement Officer were selected. Given the diversity of the communities, participants included three community residents from poorer communities, a grant recipient from the 'township', a holiday-homeowner from the affluent community, a farmer on whose land the wind-turbines were erected, and a small business owner. Finally, the municipal councillor representing the wind farm's ring-fenced $50 \mathrm{~km}$ radius of community engagement was chosen to participate. Sampling sizes differ significantly in qualitative research, and in case studies purposeful sampling that aspires towards obtaining insights into different aspects of the case or context can be used (Schreier 2018, 94). This sample size of ten was deemed sufficient to provide 'thick descriptions' of the various perspectives on the community engagement activities of the windfarm. Data collection was by means of interviews utilising a semi-structured interview schedule and were all conducted on a face-to-face basis.

The thematic analysis was guided by the seven phases of thematic qualitative text analysis proposed by Udo Kuckartz (2014) and coding was conducted using the computer assisted qualitative data analysis software of Atlas.ti. Themes and thematic sub-categories were identified from the codes and defined, text passages were allocated, and results were interpreted. 


\section{Findings}

Five themes were identified through the thematic analysis. These are detailed below.

\section{Theme one: Community challenges that influenced corporate engagement activities}

The first theme that emerged from the analysis was the socio-economic challenges community members were experiencing, such as poverty and inequality. Not only was financial poverty detailed, but 'mental poverty' was described: 'When I say mental poverty, I am talking about individuals who have lost hope, individuals who have lost belief in themselves' (Wind farm CEO, personal communication to the researchers). These challenges influenced the wind farm's community engagement strategic objectives and selection of interventions aligned to local government objectives.

\section{Theme two: Corporate community engagement strategy in partnership with communities and local government}

This theme refers to the engagement efforts of the wind farm with the community and the local government, as well as the influence that local government had on the wind farm's engagement with the communities. The engagement strategy of the wind farm considered the policies and plans for community development of local government, especially the Integrated Development Plan, in order to complement local government's objectives.

The wind farm's leadership team detailed extensive consultation and collaboration with the community and local government. These included monthly community meetings, feedback meetings, issues-based meetings, attendance at ward councillor meetings, focus groups, and informal face to face meetings. 'So, they [wind farm management] understand, they see the need of the communities, what state it is... And they are really involved, they come to the communities, we have meetings with them, we tell them what we need' (Community resident, personal communication to the researchers).

The need for an integrated approach in corporate community engagement was highlighted by participants. This required that the wind farm worked closely with local and national government to identify and address challenges (Theme 1) in the local communities. 'All of us have to participate, there is no-one behind, everyone pushes together. Government and the wind farm are doing it 50/50 for a 100\%' (Local councillor, personal communication to the researchers). This approach reflected a transformative engagement strategy depicted on the continuum of community engagement (Bowen et al. 2010) that engendered a strong relationship between the wind farm, its communities and local government (Liu et al. 2013).

\section{Theme three: Community ownership and local} government service delivery

This theme reflects the unique ownership structure of the Community Development Trust owning $26.1 \%$ of the wind farm and the dividend and revenue streams accruing in favour of the community although most community members did not know of the trust's existence. The wind farm's leadership were at pains to emphasise that funds were for the community's benefit as determined by consultation with the community and local government, but under no circumstances were these revenue streams to be utilised by local government to fund their responsibilities in terms of service delivery.

\section{Theme four: Local government in the tripartite relationship}

The role of local government, as a critical leg in the tripartite relationship of the wind farm, the communities, and itself, was the fourth theme identified. The wind farm's leadership spoke of the need for a coordinated approach between the its community engagement efforts and local and national governments' development efforts, necessitating an integration of their programmes and projects with those of local government. The CFO described their role as 'dot-connectors' between local government, national government, and the communities, but acknowledged that there were bureaucratic hurdles in working with government at national and local level (personal communication to the researchers).

Some of the engagement efforts by the wind farm were protocols by local government, especially at the inception of the wind farm when licensing permission was sought - these included public participation requirements especially around the localisation of labour, SMME support and the appointment of a community engagement officer. Others were requested by the municipality, where the contribution towards development objectives by the wind farm within the tripartite relationship was recognised by local government (Miraftab 2004). While the local municipality may approach the wind farm for support in earmarked projects, the local councillor reiterated that the final decision would rest with the community: 'If we go to the wind farm as a municipality, and can you intervene with this problem, they will tell you straight "we want to hear it from the community"' (personal communication to the researchers).

While the needs of the local communities were extensive, financial and other resources of the local government were limited, and the wind farm's significant contribution to mitigating the problem was acknowledged. While not providing local government services, the wind farm would try to determine unfunded needs in the community and to 
contribute to alleviating those needs. Community members expressed their gratitude on a number of occasions: 'I think the wind farm is playing a much bigger role than the government itself... The wind farm contributes very very big, so we are very very appreciative of their helpfulness' (Community resident, personal communication to the researchers). Considering Lumpkin and Bacq's deliberations (2019), this tripartite, cooperative relationship created regimes of support that seem to have created communal and social wealth within the wind farm's sphere of influence.

In contrast, the community regarded local government in a negative light, suggesting they were neglected by local government, and that local government was unreliable. 'The government also has to play a role, we can't just rely on the wind farm to do what the government is supposed to do... if [the wind farm] fixes everything, what about the responsibilities of the government?' (Community resident, personal communication to the researchers).

\section{Theme five: Nature of the tripartite relationship}

The complexity and importance of relationships between the wind farm, the communities and the local government resulted in 'relationships' being an identified theme. Strong relationships between the three, based on trust and transparency, were critical: 'So there is a transparent, continuous communication between ourselves and the community'. This approach resulted in the wind farm earning trust over time from the local government and their communities: 'the concept phase where there was little trust from the community... we think we have (now) earned our trust within the community, we think we are in a position to relatively speak from the same footing' (CFO, personal communication to the researchers).

The wind farm regarded themselves as an enabler for the community: 'We also play that role of being a matchmaker between the need and the intervention - not necessarily that we offer the intervention, we link people and the information' (Community engagement officer, personal communication to the researchers). This often entailed the wind farm coordinating efforts with local government to address challenges community members were experiencing. A grant recipient explains how not only did the community project receive funding from the wind farm, but the important role the wind farm played in facilitating the process of registration: 'So many people have been trying for the NPO [non-profit registration], but I got it. He assist me to go through that. And then I also got registered... my health certificate, my this, my this, my this. That man... I was just doing paperwork [laughing], this file that file. I call him, I need this and this, he says 'don't worry, I am going to assist you'. He helped me all the way, until I got through' (Grant recipient, personal communication to the researchers).

In phase 7 of the thematic qualitative text analysis, the relationship between the main categories and subcategories were further interpreted in terms of the role of local government's influence on the community engagement efforts of the wind farm with their communities, and inferences were made.

\section{Discussion: An interpretation of the moderating and mediating role of local government}

The findings suggest that the role of local government in the tripartite relationship is both moderating and mediating in nature. Moderating refers to local government's effort to regulate the community engagement efforts by the wind farm operating in their jurisdiction. Mediating is more subtle in nature and refers to the influence that local government has on the community engagement strategies of the wind farm, such as an alignment of the company's community engagement objectives to the local government's own objectives and the company's support and augmentation of local government's service delivery capacity. A reciprocal mediating role of the wind farm on local government's own community engagement with their electorate in achieving their developmental objectives, was also identified.

\section{The moderating role of local government on the wind farm's community engagement efforts}

National government played a moderating role on the wind farm's community engagement efforts the bid process and the awarding of the bid for the wind farm entailed the wind farm committing itself to community ownership through the trust of $26 \%$, and contributing a percentage of its profits towards the community. In terms of local government, the wind farm was required to obtain permission before initiating development, and local government set a number of terms of engagement for the wind farm, such as the requirement for public participation prior to development; the appointment of a community engagement officer; and that there was to be engagement with the community around issues of localisation of labour and SMME support.

Some projects undertaken by the wind farm entailed the use of assets owned by government, both local and national, such as land or municipal buildings. Other projects required permission, licences or support from local or national government, such as libraries needing the education department's support, or creches needing to comply with various regulations. These factors made it necessary for the wind farm to follow certain protocols to ensure compliance with legal requirements and obtain per- 
missions where needed for their intended projects. There was, however, no stipulation that the wind farm contribute to the local government's obligations to the community in terms of service delivery.

\section{The mediating role of local government on community engagement efforts by the wind farm}

Community engagement efforts by the wind farm took cognisance of policies and plans for community development by local government. They would therefore consult the integrated development plan to guide them in optimising outcomes of their spend and ensure they were not duplicating efforts by the local municipality, but were rather complementing the local governments existing long-term strategies - the wind farm was the 'dot-connector'. Through its intense engagement with the local communities, the wind farm would identify needs of the community, and in consultation with the local government and understanding the objectives and mandate of local government, it would craft strategies for intervention that were unfunded. The wind farm was at pains to engage extensively, not only with the community, but also with local government, and local government were always welcome to put requests for assistance to the company in non-service delivery related projects.

Reflecting on the moderating and mediating role of local government on community engagement by the windfarm, it would appear that the REIPPP programme and local development policy has provided impetus for a greater level of consultation and collaboration than has been the case in many South African companies in the past (Moloi et al. 2014; Manchidi 2015).

\section{The reciprocal mediating role of the wind farm on local government community engagement and service delivery capacity for communities they serve}

The community's perception of the local government was generally negative; it complained of being 'neglected' by the local government and of local government being unreliable. While the wind farm's CFO mentioned the bureaucratic hurdles of working with government, the wind farm had a close working relationship with the local councillor and engaged with the local government intensively. This was to ensure that their efforts complemented the socio-economic objectives of local government, acknowledging the resource constraints of the municipality. The local councillor (personal communication to the researchers) confirmed the value of the wind farm in socio-economic development: 'They [the wind farm] support us to develop and they support us to change even people in the community. They support in economic growth in the community. They support on anything, even women to become business owners.' By doing this, the wind farm mediated local governments engagement with their communities and contributed to local government's capacity for service delivery, thus bestowing communal and social wealth (Lumpkin and Bacq 2019). From the outset, the potential negative impact of the wind farm also necessitated that the local government councillor consulted with the various communities of the area.

The wind farm recognised the contribution they could make to local and national government's desire for sustainable development, and in their aligned efforts to empower communities, they developed positive interrelationships with communities and local government.

\section{The direct and indirect impact of corporate com- munity engagement, mediated and moderated by local government, on people within these communities and their development needs}

It would be remiss not to reflect on how this engagement has impacted people's lives and contributed to alleviating some of the developmental needs of the communities in question.

The selection and introduction of various wind farm community projects were the result of intensive engagement efforts between the wind farm, local government, and the communities. The wind farm's objectives were to understand their communities, to 'do-it-together', to be an enabler for personal growth of community members, and to contribute to sustainable communities.

The engagement by wind farm management and employees was often quite personal, with them developing special relationships with community members and assisting them directly when the need arose. One community member, who was awarded a grant to build a community educational facility, described how not only did the wind farm provide the funding, but how the CFO personally mentored her through the process: 'She is the kind of person that encourages you to go the right path ... give you all the support that she have to strengthen you up and give you hope' (Grant recipient, personal communication to the researchers). The term empowerment was used regularly by participants to describe the need to improve the wellbeing of those disenfranchised during apartheid, with a specific focus on women and the youth. One project was an extensive women's empowerment programme provided by the wind farm, and, as one community member suggested, these efforts were bearing fruit: 'They didn't just look at our community, they looked at us, as individual woman, for our self-esteem and everything. For me, it empowered me. It made me love my community.' (Community resident, personal communication to the researchers). 
It was made clear by the wind farm CEO that the contribution of these engagement efforts had to be sustainable: 'We have a choice of imposing our ideas on these communities because they are poor - poor people will take anything you give them however, what we have deemed to be lasting is working with the community... the last thing I would want to be part of is to come to a poor area that was able to do for themselves, and to leave them worse than they were' (personal communication to the researchers). One way the wind farm was doing this was to use local SMEs in their various construction projects, while another was their intended focus on enterprise development as a key objective of their future engagement efforts.

This strategic focus by the wind farm on promoting sustainable communities was transformational in nature as depicted on Bowen et al's continuum of community engagement. 2014) and capacitated value creation for all within the tripartite relationship, supporting the findings of Freudenreich et al. (2019) and Nijhof et al. (2019) that a strategic focus on society results in a flow of value between companies and their stakeholders.

\section{Conclusion}

This research has identified the contribution a wind farm has made to community development and the complementary role it has played in improving local government service delivery. In addition, better understanding of corporate community engagement within the tripartite relationship of the wind farm, communities and local government, has transpired.

Local government was found to have played a moderating role on corporate community engagement, as it required the wind farm to meet certain obligations in its engagement with local communities. In addition, local government played a mediating role on the wind farm's corporate community engagement efforts - the wind farm developed its strategy in alignment with the policies and plans of local government; it acted as a 'dot-connector' between the community and local government, thus contributing to local government's own objectives. The wind farm identified the needs of the community that were not funded by the local government and crafted its interventions to address these shortcomings in consultation with the local government and the communities.

The wind farm was found to play a reciprocal mediating role on local government's own engagement with the communities. As local government was grappling with financial constraints and service delivery inefficiencies, the wind farm played an important supportive function in local government's capacity for service delivery.

The wind farm recognised the contribution it could make to local and national government's desire for sustainable development, and in its aligned efforts to empower communities, it developed positive tripartite interrelationships with communities that bestowed value creation and contributed to civic wealth. These findings support and augment the understanding of value creation depicted by Nijhof et al. (2019) and Freudenreich et al. (2019) and confirm the outcome of economic, communal, and social wealth due to multi-stakeholder engagement by companies as described by Lumpkin and Bacq (2019). Thus, corporate community engagement, as a function of local government's moderating and mediating role, can lead to better service provision and improved efficiencies by local government. This contributed to the objectives of local government in providing better socio-economic opportunities for the disadvantaged communities they were mandated to service, thus substantiating Miraftab's (2004) view that the value of such tripartite relationships lies in the fact that they have the propensity to overcome certain shortcomings that local government may have in achieving their objectives.

\section{Notes}

1. The name of the local government has been anonymised to ensure confidentiality for the local government and the renewable energy company participating in the case study. The 2012 and 2016 media reports were examples of alleged corruption and service delivery issues facing the local government in the case study, while the 2018 media report presented efforts to improve governance by this municipality.

\section{Author roles}

Bryan Robinson undertook the primary research. Siân Stephens and Bryan Robinson contributed in equal measure to the paper conceptualisation, data analysis, drafting of the paper, technical editing and review.

\section{Acknowledgements}

The authors would like to express their gratitude to Dr Xiaozheng Zhang for her contributions to the initial discussions on the envisaged research. We would also like to thank our anonymous reviewer for guidance and recommendations for this article.

\section{References}

Alexander, P., C. Runciman, T. Ngwane, B. Moloto, K. Mokgele, and N. Van Staden. 2018. Frequency and Turmoils: South Africa's Community Protests 2005-2017. South African Crime Quarterly 63: 27-42. doi: https://doi.org/10.17159/2413-3108/2018/v0n63a3057. 
Bowen, F., A. Newenham-Kahindi, and I. Heremans. 2010. When Suits Meet Roots: The Antecedents and Consequences of Community Engagement Strategy. Journal of Business Ethics 95: 297-318. doi: $10.1007 / \mathrm{s} 10551-009-0360-1$.

Christensen, H. 2018. Legislating Community Engagement at the Australian Local Government Level. Commonwealth Journal of Local Governance 21: 1-30. doi: https://doi.org/10.5130/cjlg.v0i21.6515.

Davey, D. 3 April 2020. New Energy Mix on the Cards. Mail \& Guardian. https://mg.co.za/special-reports/2020-04-03new-energy-mix-on-the-cards/.

Delannon, N., E. Raufflet, and S. Baba. 2016. Corporate Community Engagement Strategies and Organizational Arrangements: A Multiple Case Study in Canada. Journal of Cleaner Production 129: 714-723. doi: 10.1016/i.jclepro.2016.03.047.

Department of Mineral Resources and Energy South Africa. 2020. Renewable Energy. http://www.energy.gov.za/files/renewables frame.html.

Eberhard, A. and R. Naude. 2016. The South African Renewable Energy Independent Power Producer Procurement Programme: A Review and Lessons Learned. Journal of Energy in Southern Africa 27 (43): 1-14.

Freeman, R.E. 1984. Strategic Management: A Stakeholder Approach. Boston: Pitman.

Freudenreich, B., F. Lüdeke-Freund, and S. Schaltegger. 2019. A Stakeholder Theory Perspective on Business Models: Value Creation for Sustainability. Journal of Business Ethics 166: 3-18. doi: $\underline{\text { https://doi.org/10.1007/s10551-019-04112-z. }}$

Hamann, R. 2004. Corporate Social Responsibility, Partnerships, and Institutional Change: The Case of Mining Companies in South Africa. Natural Resources Forum 28: 278-290. doi: https://doi.org/10.1111/i.1477-8947.2004.00101.x.

Helmsing, A. H. J. 2003. Local Economic Development: New Generations of Actors, Policies and Instruments for Africa. Public Administration and Development 23 (1): 67-76. doi: https://doi.org/10.1002/pad.260.

Moloi, K. C., A. Oksiutycz-Munyawiri, and G. Ndong. 2014. An Investigation of Corporate Social Investment (CSI) Programme's Contribution to the Brand Image of a Financial Institution in Alexandra, South Africa. Mediterranean Journal of Social Sciences 5 (4): 282-291. doi: http://dx.doi.org/10.5901/mjss.2014.v5n4p282.

IPP Projects. 2020. Independent Power Producer Procurement Programme. https://www.ipp-renewables.co.za/.

Institute of Directors of South Africa. 2016. King IV Report on Corporate Governance for South Africa. https://www.iodsa.co.za/page/AboutKingIV.

Kackartz, U. 2014. Three Basic Methods of Qualitative Text Analysis. Chap. 4 in Qualitative Text Analysis: A Guide to Methods, Practice and Using Software. London: SAGE. doi: $10.4135 / 9781446288719$.

Kim, Y. and N. Darnall. 2015. Business as a Collaborative Partner: Understanding Firms' Sociopolitical Support for Policy Formation. Public Administration Review 76 (2): 1-12. doi: https://doi.org/10.1111/puar.12463.

Leedy and Ormrod. 2005. Practical Research: Planning and Design. $8^{\text {th }}$ ed. New Jersey: Pearson Merrill Prentice Hall.

Liu, G., T. Eng, and W. Ko. 2013. Strategic Direction of Corporate Community Involvement. Journal of Business Ethics 115 (3): 469-487. doi: https://doi.org/10.1007/s10551-012-1418-z.

Lorenz, C., G. Gentile, and T. Wehner. 2013. Exploring Corporate Community Engagement in Switzerland: Activities, Motivations, and Processes. Business \& Society 55 (4): 594-631. doi: $10.1177 \% 2 \mathrm{~F} 0007650313482549$.

Lumpkin, G. T., and S. Bacq. 2019. Civic Wealth Creation: A New View of Stakeholder Engagement and Societal Impact. Academy of Management Perspectives 33 (4): 383-404. doi: https://doi.org/10.5465/amp.2017.0060.

Manchidi, S. 2015. Factors Necessary to Enhance the Effective Implementation of Corporate Social Investment (CSI) in South Africa. PhD. (Business Management)/ M.Com. [Unpublished]: University of Johannesburg. file:///C:/Users/User/Downloads/Factors\%20Necessary\%20to\%20Enhance\%20the\%20Effective\%20Implementation\%20of\%20Corporate\%20Social\%20Investment\%20(Csi)\%20In\%20South\%20Africa.pdf.

Mersham, G. M., and C. Skinner. 2016. South Africa's Bold and Unique Experiment in CSR practice. Society and Business Review 11 (2): 110-129. doi: https://doi.org/10.1108/SBR-04-2016-0027.

Miraftab, F. 2004. Public-Private Partnerships: The Trojan Horse of Neoliberal Development? Journal of Planning Education and Research 24 (1): 89-101. doi: https://doi.org/10.1177\%2F0739456X04267173.

Mujere, J. 2015. Insurgent Citizenship and Patterns of Authority in Mining Affected Areas: Understanding Community Protests in Rustenberg, South Africa. Labour, Capital and Society 48 (1 and 2): 240-266.

Municipality X local newspaper. 2012. [Online]. [Accessed: 17 August 2020]. 
Municipality X MEC policy speech. 2016. [Online]. [Accessed: 17 August 2020].

Municipality X Municipal website. 2018. [Online]. [Accessed: 17 August 2020].

Nijhof, A. J. Schaveling, and N. Zalesky. 2019. Business, Society, and the Need for Stewardship Orientation. Journal for Organizational Change 32 (1): 145-163. doi: https://doi.org/10.1108/JOCM-09-2017-0348.

Rolfe, S. 2016. Divergence in Community Participation Policy: Analysing Localism and Community Empowerment Using a Theory of Change Approach. Local Government Studies 42 (1): 97-118. doi: 10.1080/03003930.2015.1081848.

Schaffner, J. 2014. Development Economics. USA: Wiley.

Schreier, M. 2018. Sampling and Generalization. In Flick, U. (Ed.), The SAGE Handbook of Qualitative Data Collection (pp. 84-98). London: SAGE.

South African Government. 2020. Mineral and Petroleum Resources Development Act 28 of 2002 (Amended). https://www.gov.za/documents/mineral-and-petroleum-resources-developmentact?gclid=Cj0KCQjwhb36BRCfARIsAKcXh6FwqhTXRS pX1bmlSZfHtKyyQpQZGx3o9jQKYiHc8wF95HeT-16urEaApgQEALw_wcB.

Stirling, L., A. Wilson-Prangley, G. Hamilton, and J. Olivier. 2016. Antecedents to Transformational Community Engagement in South Africa. South African Journal of Economic and Management Sciences 19 (4). doi: https://dx.doi.org/10.17159/2222-3436/2016/v19n4a4.

Vasstrøm, M. and R. Normann. 2019. The Role of Local Government in Rural Communities: Culture-based Development Strategies. Local Government Studies 45 (6): 848-868. doi: https://0-doi.org.wam.seals.ac.za/10.1080/03003930.2019.1590200.

Wlokas, H., P. Westoby, and S. Soal. 2017. Learning from the Literature on Community Development for the Implementation of Community Renewals in South Africa. Journal of Energy in Southern Africa, 28 (1): 35-44.

Worthington, I., D. Patton, and I. Lindley. 2003. Local Authorities, Business and LA21: A Study of East Midlands Sustainable Development Partnerships. Local Government Studies 29 (1): 91-110. doi: https://0-doi.org.wam.seals.ac.za/10.1080/714004179. 